\title{
A Nephro-Obstetric outpatient clinic model
}

\author{
Estela Nogueira ${ }^{1}$, Rita Calça ${ }^{2}$, Iolanda Godinho ${ }^{1}$, Luisa Pinto ${ }^{3}$ \\ ${ }^{1}$ Division of Nephrology and Renal Transplantation, Department of Medicine, Centro Hospitalar Lisboa Norte, EPE \\ ${ }^{2}$ Nephrology Department, Centro Hospitalar de Lisboa Ocidental, EPE \\ ${ }^{3}$ Department of Obstetrics, Centro Hospitalar Universitário Lisboa Norte, EPE
}

\section{ABSTRACT}

Chronic kidney disease (CKD) is increasing worldwide and studies estimate that around $6 \%$ of women of childbearing age suffer from kidney disease. Preconception counselling of women with CKD and their management during pregnancy requires a multidisciplinary team, with both nephrologists and obstetricians experienced in advising and taking care of women across the CKD spectrum, including dialysis patients and women with a kidney transplant.

Here, the authors describe a model of a Nephro-Obstetric outpatient clinic, created in 2011, detailing their current clinical experience in the management of this complex population of women.

Key words: Chronic kidney disease, counseling, dialysis, pregnancy, pre-natal management, renal transplantation

\section{INTRODUCTION}

Portugal has one of the highest rates of CKD in Europe. Studies estimate that around $6 \%$ of women of childbearing age have CKD, and this incidence will probably rise in the forthcoming years, due to late motherhood and increasing incidence of CKD. ${ }^{1}$

Pregnancy in patients with CKD is associated with worse outcomes than in healthy pregnant women. The management of these pregnancies is highly challenging for both nephrologists and obstetricians. ${ }^{1-4}$

Therefore, multidisciplinary specialized care is of maximum importance to minimize risks and optimize outcomes. Additionally, preconception counselling plays a crucial role in defining the safest timing for pregnancy, leading to a decrease in possible complications such as fetal malformations, renal function deterioration, preeclampsia and fetal growth restriction.

\section{STRUCTURE OF A NEPHRO-OBSTETRIC OUTPATIENT CLINIC}

The Nephro-Obstetric outpatient clinic at Centro Hospitalar Lisboa Norte/Hospital Santa Maria was created in 2011, in a collaborative initiative between the nephrology and obstetric departments.

The Maternal Fetal Clinic (MFC) was already working with a multidisciplinary team that involved rheumatology, infectiology and clinical genetics. Nephrology started its participation with the clinic at that time (2011), to assist in the care of CKD patients.

Clinical activity occurs at the obstetric department facilities on a monthly basis. Shared clinical processes allow a more efficient management and a constant communication between all the specialists involved. To optimize clinical care and reduce time consumption, patients are seen by different medical specialties on the same day. For example, a patient with polycystic kidney disease can have an appointment with the nephrologist, obstetrician and the clinical geneticist on the same day. Additionally, clinical evaluation can be completed by nutritional and nurse assessment.

\section{PRECONCEPTION COUNSELLING AND OPTIMIZATION}

Prepregnancy counselling can be quite challenging due to the scarcity of solid evidence on how to advise women with CKD of diverse etiology. Pregnancy in women with advanced CKD, stages 3 to 5 , is even more delicate as fertility is decreased, the occurrence of pregnancy reduced and data on pregnancy outcomes very limited.

Women are referred by nephrologists, obstetricians and general practitioners. Counselling is made by an obstetrician and a nephrologist experienced in the management of pregnancies complicated by CKD. In complex cases, counselling is given at the same time, as a discussion concerning the possibility of anticipating renal replacement therapy is often necessary. Women's partners are invited to attend to participate in the shared decision process.

Individualized advice is given based on the available recent scientific evidence, mainly focusing on fertility and its decrease as CKD progresses, the impact of pregnancy on kidney function, and maternal and fetal complications associated with CKD.

In cases of hereditary nephropathy, patients are additionally counselled by a clinical geneticist on the risk of transmission to the offspring 
and the possibility of prenatal diagnostic testing, preimplantation genetic diagnosis and conception via germ cell donation. In some patients, genetic diagnosis can be made for the first time as available tests have been evolving significantly in the last few years.

In women with immune mediated disease (such as glomerulonephritis or systemic rheumatic disease), baseline disease activity is thoroughly evaluated and characterized for risk stratification and establishment of the best timing for pregnancy. If the disease is stable for at least 6 months, therapy is then adjusted for conception, with a complete reassessment 3 to 6 months later, to ensure that remission is maintained with the new therapy.

Angiotensin converting enzyme inhibitors (ACE) should ideally be withheld at least 6 weeks before pregnancy. However, in patients with proteinuria $>1 \mathrm{~g} /$ day, UK NICE guidelines advise maintaining ACEs until conception with frequent pregnancy tests in order to achieve an early diagnosis of pregnancy. Decisions to maintain these drugs are thoroughly discussed considering fertility issues and the possibility of delayed pregnancy without nephroprotection as teratogenicity issues seem to occur mainly with second and third trimester exposure. Angiotensin receptor blockers (ARB) are stopped and converted to another anti-hypertensive drug 6 weeks before conceiving, as data regarding their safety in the first trimester is still lacking.

In Diabetic patients tight glycemic and blood pressure control is warranted in the 6 months prior to conception, to achieve better outcomes in pregnancy and to decrease the risk of malformations. Management of proteinuria should also be optimized.

Women with a kidney transplant are advised to delay conception for at least 1 year after transplantation as this period is particularly prone to graft rejection and to potentially teratogenic infections. Contraceptive counselling is also discussed, as fertility is usually reestablished during the first 6 months after transplantation. Ideal conditions for conception include good graft function $(\mathrm{Cr}<1.5 \mathrm{mg} /$ $\mathrm{dl}$, proteinuria $<500 \mathrm{mg} /$ day), lack of graft rejection in the last year and absence of active teratogenic infections (namely citomegalovirus)..${ }^{5}$ Assuring these conditions significantly reduces the risk of graft function deterioration and acute rejection. During pregnancy, the risk of graft rejection is low, with an incidence reported in the literature of around 3 to $4 \% .{ }^{6}$ Immunosuppression must be adjusted (mTOR inhibitors and mycophenolate mofetil must be withheld) with graft reevaluation 3 to 6 months later to ensure stable function with the new therapy.

In the past decade, the pregnancy rate in women on dialysis has been increasing, possibly due to intensive dialysis schedules, including nocturnal dialysis. ${ }^{7}$ Additionally, after Hladenuwich et al's publication of more favorable maternal and fetal outcomes during pregnancies involving intensive dialysis, counselling has changed considerably in this specific population. ${ }^{8,9}$ Nevertheless, pregnancy outcomes are still better in transplanted women. As such, patients are usually advised to postpone pregnancy until after transplantation. However, women with advanced age or hyperimmunized women will have a narrow window of opportunity, meaning that the only possibility of conception will be while on dialysis.
When there is a high risk of graft failure, as in atypical/genetic hemolytic uremic syndrome, risk versus benefit of allowing conception while on dialysis is discussed. Pregnancy while on dialysis requires substantial life adjustment due to increased weekly dialysis time, possibly impinging on professional activity. Furthermore, being a mother while on dialysis may be considerably challenging, especially considering the possibility of having a premature child with disabilities. All these aspects should be discussed during counselling, focusing on the need to prepare adequate post-natal support.

Pregnancy is a risk factor for hyperimmunization and although it is difficult to individualize the possibility of alloimmunization, women need to acknowledge that possibility and its impact on transplantation. ${ }^{10}$

At the preconception appointment, patients are given flyers with information, to help them clarify their doubts and integrate all the information they have been given, with the possibility of scheduling another appointment if needed.

\section{PRENATAL MANAGEMENT OF PREGNANT WOMAN IN CKD STAGES G1 TO 5}

CKD pregnant women are evaluated monthly or twice a month until the end of the second trimester, and then twice a month or weekly in the third trimester, depending on clinical conditions.

Blood pressure (BP) monitoring at home is strongly recommended and records are evaluated at each appointment. Target levels in pregnant CKD patients is still a matter of debate, as solid evidence on this specific population is still lacking. Concerns over the reduction of uteroplacental blood flow with subsequent fetal harm is the main argument against treating hypertension in a manner similar to that in a nonpregnant state. Strong evidence that tight hypertensive control reduces maternal and fetal complications (CHIPS study) is lacking. ${ }^{11}$ However, most trials excluded patients with CKD. Furthermore, studies have reported worse maternal and fetal outcomes in CKD patients with previous chronic hypertension or poorly controlled hypertension during pregnancy. ${ }^{12}$ As such, in patients with CKD, most authors aim for $\mathrm{BP}<140 / 90 \mathrm{mmHg}$ according to the American College of Obstetricians and Gynecologists (ACOG) guidelines published in 2013 and more recently (2019) from the UK National Institute for Health and Care Excellence (NICE), which target BP of $135 / 85 \mathrm{mmHg}$ and not below $110 / 70 \mathrm{mmHg}$. ACOG Guidelines were also updated this year and recognize the need for a better control in patients with CKD, although specific levels are not defined. ${ }^{13-15}$

Table I and II provide hypertensive disorders definitions and antihypertensive agents used in CKD pregnant women.

Blood and urine analysis are performed every month with increased frequency (twice a month or weekly) by the second and third trimester, especially in more advanced CKD (G3-5) or when signs of complications arise, such as worsening hypertension, hemolytic anemia, thrombocytopenia, hepatic dysfunction, increase in proteinuria or serum creatinine ( $\mathrm{SCr}$ ). Renal function evaluation in pregnant women is difficult as none of the available GFR formulas are validated in pregnancy and all underestimate it. ${ }^{16,17}$ Creatinine clearance is still 


\section{Table I}

Hypertensive Disorders adapted from the ACOG guidelines 2019

\begin{tabular}{|c|c|}
\hline Hypertension in pregnancy & $\mathrm{sBP}>140 \mathrm{~mm} \mathrm{Hg}$ or dBP $>90 \mathrm{~mm} \mathrm{Hg}$, or both, twice at least 4 hours apart \\
\hline Severe-range hypertension & $\mathrm{sBP}>160 \mathrm{~mm} \mathrm{Hg}$ or $\mathrm{dBP}>110 \mathrm{~mm} \mathrm{Hg}$, or both, twice at least 4 hours apart \\
\hline Chronic hypertension & $\begin{array}{l}\text { Hypertension before pregnancy or } 20 \text { weeks of gestation; or hypertension that is diagnosed for the first time during pregnancy } \\
\text { and that does not resolve in the postpartum period }\end{array}$ \\
\hline Preeclampsia & $\begin{array}{l}\text { Hypertension post } 20 \text { weeks of gestation in a previously normotensive patient and the new onset of } 1 \text { or more of the following: } \\
\text { - Proteinuria }>0.3 \mathrm{~g} / \text { day }(24 \mathrm{~h} \text { urine) or protein/creatinine ratio }>0.3 \mathrm{mg} / \mathrm{mg} \text { or dipstick }>2+\text {; } \\
\text { - Serum creatinine }>1,1 \mathrm{mg} / \mathrm{dl} \text { or doubling of } \mathrm{sCr} \text { in absence of renal disease; } \\
\text { - Platelet count }<100,000 / \text { microL; } \\
\text { - Aminotransferases }>2 \text { times above reference levels; } \\
\text { - Pulmonary edema; } \\
\text { - Cerebral or visual symptoms. }\end{array}$ \\
\hline $\begin{array}{l}\text { Chronic hypertension with } \\
\text { superimposed preeclampsia }\end{array}$ & $\begin{array}{l}\text { Preeclampsia in a woman with a history of hypertension before pregnancy or before } 20 \text { weeks of gestation } \\
\text { - Precise definition not available and difficult in women with previous hypertension and proteinuria. } \\
\text { - To be considered if sudden aggravation of hypertension/proteinuria and organ dysfunction (renal/hepatic/hematologic/neuro- } \\
\text { logic/pulmonary) or sflt-1/PIGF compatible with PE. }\end{array}$ \\
\hline
\end{tabular}

Legend: Systolic blood pressure (sBP), diastolic blood pressure (dBP).

\section{Table II}

Anti-hypertensive drugs in CKD pregnant woman

\begin{tabular}{|c|c|c|}
\hline & Drug & Comment \\
\hline First line & $\begin{array}{l}\text { Methyldopa } 250-3000 \mathrm{mg} / \text { day (divide into } 2-3 \text { doses) } \\
\text { Nifedipine (long acting) } 30-120 \mathrm{mg} / \text { day (divided into } 2 \text { doses) }\end{array}$ & $\begin{array}{l}\text { Dose limited by side effects (headache, sedation etc.). Low effect if } \\
\text { severe HT. }\end{array}$ \\
\hline Second line & $\begin{array}{l}\text { Beta blockers } \\
\text {-Metoprolol } 50-450 \mathrm{mg} / \text { day (divided into } 2 \text { doses) } \\
\text { Clonidine } 0.1 \mathrm{mg}-0.9 \mathrm{~m} / \text { day (divided into } 2 \text { or } 3 \text { doses) } \\
\text { Doxazosine } 4 \mathrm{mg}-16 \mathrm{mg} / \text { day } \\
\text { Diuretics - furosemide or thiazides }\end{array}$ & $\begin{array}{l}\text { Overall safe, but limited data. Avoid atenolol. Metoprolol has more } \\
\text { data. } \\
\text { Same effect as methyldopa. Clonidine more potent. } \\
\text { To be avoided, as it provokes diuresis in fetus and possibly volume } \\
\text { depletion/placental perfusion }\end{array}$ \\
\hline
\end{tabular}

the preferred method for the measurement of kidney function in pregnancy, although dilated urinary system will reduce its precision. However, this method is cumbersome, so most authors will use $\mathrm{SCr}$, and this is also our practice. Renal physiological adaptation in normal pregnancy is associated with an increase in GFR of around $40 \%$ in the first trimester, due to renal plasma flow increment and other factors such as reduced glomerular intracapillary oncotic pressure. Knowledge of these changes is critical to the understanding of $\mathrm{SCr}$ variation during pregnancy. $\mathrm{SCr}>0.9 \mathrm{mg} / \mathrm{dl}$ is therefore considered pathological.

It is important to emphasize that during pregnancy, even subtle increases in $\mathrm{SCr}$ could imply a significant decrease in GFR, as was shown in a study published by Hladunewich et al. The study evaluated GFR in preeclamptic women and concluded that an increase in $\mathrm{SCr}$ of $0.2 \mathrm{mg} / \mathrm{dl}$, even if within the normal range, could mean a loss of GFR of about $50 \% .{ }^{18}$ As such, we usually use serum creatinine to assess kidney function, closely monitoring even small rises.

Proteinuria is usually evaluated using first morning urine proteinto-creatinine ratio (PCR), although in patients with pre-existent high-level proteinuria or above $>1 \mathrm{~g} /$ day, a $24 \mathrm{~h}$ proteinuria is performed in order to precisely detect variations among the different trimesters. Recent studies have revealed that PCR in random spot urine has poor correlation with $24 \mathrm{~h}$ proteinuria, especially when therapeutic decisions need to be made. ${ }^{19}$

To partially overcome this issue, patients are always told to collect first morning samples, and trends in protein excretion are evaluated. Pregnancy is associated with a physiologic decrease in tubular protein reabsorption. Therefore, a level of proteinuria only above $300 \mathrm{mg} /$ day is considered pathologic.

It is well known that pregnancy is by itself a risk factor for venous thromboembolism. In heavy proteinuric patients this risk is further increased, and most authors will recommend thromboprophylaxis. Data to precisely define the cut-off of proteinuria above which to start low molecular weight heparin (LMWH) are still lacking, but NICE guidelines in diabetes recommends its use above $5 \mathrm{~g} /$ day. Prevention should also be considered in nephrotic proteinuria with severe hypoalbuminemia (below $2 \mathrm{~g} / \mathrm{L}$ ), or in less severe proteinuria if other risk factors 
are present, such as obesity or immobility. Prevention should be maintained until the 6 th week postpartum. ${ }^{20}$

Recently published clinical practice guidelines in pregnancy and renal disease from the UK Renal Association (RA) recommends the use of thromboprophylaxis in patients with nephrotic range proteinuria, and considering its use in patients with non-nephrotic proteinuria when additional risk factors are present. ${ }^{21}$

Patients with systemic immune mediated disease with kidney involvement are carefully evaluated at preconception to discard active disease, stratify risk and optimize timing of conception. Women with lupus nephritis and proteinuria $>1 \mathrm{~g} /$ day after ACE/ARB suspension should ideally be submitted to biopsy (prepregnancy) to exclude active nephritis, which is associated with unfavorable outcomes. ${ }^{22}$ Full autoantibodies and complement are evaluated to assess baseline activity and the risk of neonatal lupus or congenital heart block, especially in patients Ro/SSA or La/SSB positive. Antiphospholipid antibody screening is also necessary to define the need for low dose aspirin and/or LMWH according to recently published EULAR guidelines. ${ }^{23}$ During pregnancy, immunologic monitoring is mainly performed with dsDNA antibody and complement levels, bearing in mind that C3 and C4 levels (being acute phase proteins) usually increase during normal pregnancy. Hydroxychloroquine should be maintained or added in all pregnant women with lupus as it reduces the possibility of flares (including renal flares), infection, thrombosis, congenital heart block and intrauterine growth restriction. ${ }^{22,24}$

The use of azathioprine, cyclosporine A, tacrolimus and low dose steroids during pregnancy is safe. Lupus flares can be managed with these agents. When severe flares occur, intravenous glucocorticoids pulse therapy, intravenous immunoglobulin and plasmapheresis can be considered. In recent years, several studies have revealed successful management of renal flares with tacrolimus monotherapy. ${ }^{25}$

De novo Glomerulopathy during pregnancy is rare but when it occurs, especially if associated with nephrotic syndrome or renal dysfunction, renal biopsy is warranted. It is consensual that after 30-32 weeks, no woman should be biopsied, as the risks of prematurity decrease significantly after that time and the best option would be to anticipate delivery and perform the biopsy afterwards. The best evidence on this issue comes from a systematic review of 39 studies, with 243 and 1236 biopsies done during and after pregnancy respectively. Relevant complications were found in $7 \%$ of reported biopsies performed during pregnancy versus $1 \%$ performed after delivery. Of these, $2 \%$ were major complications and occurred between the $23^{\text {rd }}$ and the $26^{\text {th }}$ week of pregnancy. ${ }^{26}$ As such, if necessary, biopsies should be performed before 23 weeks.

In pregnant CKD women, urine culture is performed every month. Although, asymptomatic bacteriuria is almost never treated, recent 2019 Infectious Disease Society of America guidelines still recommend its treatment during pregnancy with a 4-7-day course of antibiotics. The rationale behind this attitude relies on reducing the risk of acute pyelonephritis and, therefore, of preeclampsia, premature birth and low birth weight, as well as other complications such as acute renal failure. ${ }^{27}$ Furthermore, after the second urinary tract infection (UTI) during pregnancy, especially in patients with increased risk of UTI recurrence (immunosuppressed patients or patients with congenital anomalies of the kidney and urinary tract), antibiotic prophylaxis is prescribed until the end of pregnancy.

Pregnant CKD women have an increased risk of developing preeclampsia (PE), as well as kidney donors. As such, low-dose aspirin (75-150mg at night) should be started before the $16^{\text {th }}$ week. Calcium supplementation as a measure to reduce PE is not consensual and according to UK RA guidelines, it is not recommended in this population as it could increase positive calcium balance with cardiovascular long-term consequences. ${ }^{21}$

BP monitoring at home is essential for the early diagnosis of PE. When BP increases, close surveillance is warranted, with antihypertensive drug adjustment, laboratory monitoring to detect organ repercussion and vigilance of fetal wellbeing. In the presence of any signs of $\mathrm{PE}$ or renal dysfunction, patients are admitted for tight surveillance of maternal and fetal health. SfIt-1/PIGF ratio (soluble fms-like tyrosine kinase 1 / placental growth factor) can help in the differential diagnosis of renal dysfunction due to PE or to other causes, namely relapse of previously known kidney disease. ${ }^{28,29}$ A negative result can still be $P E$, and should be repeated later on, if the clinical picture is compatible with PE.

A decision to anticipate delivery is always multidisciplinary, taking into consideration the risk of prematurity and the possibility of permanent renal function loss. The patient (and partner) should be involved in the decision process, as sometimes, 'only' renal dysfunction is present and no other maternal or fetal threatening signs demand pregnancy termination. As such, in individual cases with mild to moderate kidney dysfunction and gestation below 30 weeks, pregnancy is prolonged according to renal function stability and mother's desire to reduce the risk of very early prematurity. In those cases, dialysis anticipation must be thoroughly discussed.

Regarding PE treatment, there is some enthusiasm regarding sFlt-1 removal by therapeutic apheresis. In a pilot study, Ravi Thadhani showed that this therapy could prolong pregnancy by 8 to 15 days, with one or more sessions of apheresis. However, a proof-of-concept trial (SAVE) is ongoing and this potential therapy is still unavailable. ${ }^{30}$

In patients with CKD and PE, it is important to emphasize that there is an increased risk of pulmonary edema and, therefore, continuous and careful volemia assessment is mandatory.

One of the questions that remains unanswered is what cut-off should be used to initiate dialysis in patients with advanced CKD or with CKD that progresses during pregnancy. There is insufficient data to establish this cut-off. However, considering the historical observational data that urea is fetotoxic, especially at levels above $17 \mathrm{mmo} / \mathrm{L}$ $(102 \mathrm{mg} / \mathrm{dl})$, the expert panel responsible for the recently published UK RA guidelines recommends that if renal function deteriorates and serum urea is above $15 \mathrm{mmol} / \mathrm{L}(90 \mathrm{mg} / \mathrm{dl})$, discussion about initiating dialysis should occur. The decision to start dialysis should balance the risks, benefits and logistics of dialysis initiation in pregnancy with the risks of preterm delivery before dialysis initiation if the gestation is approaching or more than 34 weeks. 
Additionally, the guideline committee advocates that until there is strong evidence to intensify dialysis in patients commencing dialysis during pregnancy, initiation of dialytic therapy during pregnancy should be 'gentle' (example $2 \mathrm{~h}$ 3times a week), with subsequent titration according to biochemical parameters, as well as maternal and fetal wellbeing. ${ }^{21}$

As mentioned above, in patients with diabetic nephropathy, both glycemic and blood pressure control and proteinuria management must be optimized in preconception to reduce the incidence of complications, including malformations. During pregnancy, proteinuria frequently increases, due to hyperfiltration and an increase in glomerular permeability associated with the progressive rise of sFlt-1 level during gestation. ${ }^{28,29}$ In our outpatient clinic, thromboprophylaxis is usually initiated when proteinuria reaches nephrotic levels, as defined by UK RA guidelines. Tight glycemic control must be achieved and consequently patients are closely managed by both an endocrinologist and a nutritionist experienced in obstetrics.

\section{PRENATAL MANAGEMENT OF PREGNANT WOMEN ON DIALYSIS}

Historically, patients on dialysis would be discouraged from getting pregnant, as maternal and fetal outcomes reported in the literature were very poor. Furthermore, the available data were sparse, as the fertility rate in dialysis women was very low, with a pregnancy incidence of 0.3 per 100 patient years. ${ }^{31-32}$ Over the last decades, and possibly due to innovation in dialysis, pregnancy rates have progressively increased, with rates of 1 to $7 \%$ in some series, even reaching 15 to $20 \%$ in patients on intensive nocturnal hemodialysis. ${ }^{2,32,33}$

Increased uremic clearance with reduction of prolactin levels could play a role in normalizing the usual disturbance in the hypothalamicpituitary-gonadal axis that is seen in childbearing-age women on dialysis. This was shown in the Toronto study in which intensively dialyzed patients experienced the return of regular menstrual cycles and an increased fertility incidence of 15 to $20 \% .{ }^{34,35}$ Therefore, some authors discuss the possibility of increasing dialysis dose or switching to nocturnal dialysis to increase the possibility of fertility in some patients.

Pregnancy in women on peritoneal dialysis (PD) seems to be less likely than in women on hemodialysis, possibly due to hypertonic dextrose solutions and the fluid-filled peritoneum that can interfere with ovum transit to the uterus. ${ }^{33}$ Although the reasons remain unclear, if fertility is pursued, transition to intensive hemodialysis schedules should probably be proposed.

Pregnancy diagnosis in women on dialysis is typically delayed (sometimes until the $20^{\text {th }}$ week of gestation or later) since menses are frequently irregular and weight gain, nausea and vomiting are common in these patients. Furthermore, human chorionic gonadotropin levels are frequently positive (low levels) in women with CKD stage 5 , as they correlate inversely with creatinine clearance, contributing to uncertainty in the diagnosis. ${ }^{36}$ If pregnancy is suspected, an ultrasound should be performed as soon as possible to confirm the diagnosis, fetal viability and gestational age.
The most important paradigm shift in pregnancies with ESRD relies on the recent evidence that increasing dose-delivered dialysis improves pregnancy outcomes. The Hladunewich group published a study comparing pregnancy outcomes from 22 pregnancies in the Toronto Pregnancy and Kidney Disease Clinic and Registry (2000-2013) with outcomes from 70 pregnancies in the American Registry for Pregnancy in Dialysis Patients (1990-2011). Patients dialyzed 20h/week had a 48\% live birth rate compared to $85 \%$ in woman dialyzed $36 \mathrm{~h}$ per week. Additionally, duration of pregnancy increased significantly from 27 weeks to 36 weeks, and birth weight raised from 1748 vs $2118 \mathrm{~g}{ }^{9}$

Currently, it is consensual that dialysis dose should be increased in pregnancy. Dialysis prescription itself varies according to different practices. Renal residual function must be considered when defining dialysis dose. Recently published UK RA guidelines recommend switching from $\mathrm{PD}$ to $\mathrm{HD}$ and prescribing long, frequent hemodialysis, aiming for pre-dialysis urea $<75 \mathrm{mg} / \mathrm{dl}^{21}$

Other authors will aim for pre-dialysis urea of $60-90 \mathrm{mg} / \mathrm{dl}$ and define that minimum dialysis dose in pregnancy will be typically $36 \mathrm{~h} /$ week (6h/day, 6 times a week). ${ }^{37}$

At our unit, we aim for $36 \mathrm{~h} /$ week, with urea $<60 \mathrm{mg} / \mathrm{dl}$, although this schedule is highly challenging for patients requiring individualization, especially in patients with residual renal function. Ideally, patients should be on nocturnal dialysis, but dialysis centers usually do not have the availability to offer this dialysis schedule, except during the day.

Dialysis prescription, therapy and diet should also be adapted to pregnancy, as detailed in Table III.

During the second and third trimesters, blood analysis should be performed at least biweekly, and then weekly if blood pressure levels increase or if there is any sign of PE. It is very difficult to diagnose PE in patients on dialysis. This diagnosis relies mainly on BP aggravation, hemolytic anemia, thrombocytopenia and liver dysfunction. Signs are frequently mild, but should always be closely monitored, as should fetal well-being. sFlt1/PIGF ratio can be helpful in the diagnosis of PE.

Regarding obstetric care, it is worth emphasizing that first trimester screening tests have flaws where dialysis patients are concerned. Therefore, if possible, screening with cell-free DNA in maternal blood should be offered.

Fetal monitoring involves obstetric ultrasounds at 12, 21, 28, 32 and 36 weeks and weekly cardiotocography starting at 32 weeks.

If magnesium sulphate is used for neuroprotection or in the prevention of eclampsia, a loading dose of 4 to $6 \mathrm{~g}$ is administered over 20 to 30 minutes, with close monitoring of magnesium levels and signs of toxicity. Maintenance dose is not used in these patients.

Route of delivery should be decided according to obstetric criteria.

It is of utmost importance that these patients are surveyed at a tertiary center, where both obstetrics, nephrology and neonatology can provide specialized care in such a complex situation. 


\section{Table III}

Dialysis and therapy adjustment to pregnancy

\begin{tabular}{|c|c|}
\hline & Dialysis prescription \\
\hline $\begin{array}{l}\text { Bath } \\
\text { - HCO3 } 25-28 \mathrm{meq} / \mathrm{l} \text { (to avoid alcalemia); } \\
\text { - } \mathrm{K} 3 \mathrm{meq} / \mathrm{l} \\
\text { - Ca } 1.5 \mathrm{mmol} / \mathrm{l} \\
\text { - Phosphate supplementation } \\
\text { Ultrafiltration minimized } 1500 \mathrm{ml} / \text { dialysis } \\
\text { Minimized Unfractionated heparin } \\
\text { BP goal } 120-140 / 70-90 \\
\text { Dry weight increase } 1.5 \mathrm{~kg} \text { (1st Trimester), } 0.3-0.5 \mathrm{~kg} / \text { week }\end{array}$ & $\begin{array}{l}\text { Avoid alkalemia; adjust according to blood levels } \\
\text { Avoid diet restriction } \\
\text { Hypophosphatemia is common; effervescent phosphorus 500mg 1-2 times/day usually needed. } \\
\text { Ultrafiltration must be individualized } \\
\text { To avoid bleeding, but is safe in pregnancy } \\
\text { To avoid reducing uteroplacental flow } \\
\text { Individually adjust }\end{array}$ \\
\hline & Therapy \\
\hline $\begin{array}{l}\text { Target Hemoglobin } \sim 10-11 \mathrm{~g} / \mathrm{dl} \text { with erythropoietin stimulating agent } \\
\text { Iv iron safe } \\
\text { Double folic acid and Vitamin B dose } \\
\text { AAS } 100 \mathrm{mg} \text { day (after } 12 \text { weeks) } \\
\text { Calcitriol and cholecalcipherol safe to use } \\
\text { Avoid Calcimimetic, sevelamer } \\
\text { Protein intake } \sim 1.5-1.8 \mathrm{mg} / \mathrm{kg} / \text { day }\end{array}$ & $\begin{array}{l}\text { Safe to use in pregnancy } \\
\text { Not validated in dialysis, but used if possible } \\
\text { Hyperparathyroidism usually stabilize } \\
\text { Adjusted by nutritionist }\end{array}$ \\
\hline
\end{tabular}

\section{PRENATAL MANAGEMENT IN PREGNANT WOMAN WITH RENAL TRANSPLANT}

Renal transplant patients have an increased risk of PE ( 30\%), and AAS is usually started between the 12th and the 16th weeks, as recommended by UK RA clinical practice guidelines on post-operative care of kidney transplant recipients. ${ }^{5}$

After conception, careful monitoring of calcineurin inhibitor serum levels is carried out, as there is usually an abrupt decrease of CsA and tacrolimus levels in the first trimester. In some patients, pre-pregnancy dose can be duplicated without reaching therapeutic levels. However, there is some evidence that during pregnancy, unbound tacrolimus levels are stable even when whole blood tacrolimus decreases, which means that there is a possibility that we should not increase the dose. ${ }^{38}$ Unfortunately, measuring unbound tacrolimus is unfeasible in clinical practice. Currently, although some authors advocate that adjusting the dose is unnecessary, most renal physicians will increase tacrolimus and CsA dose targeting therapeutic levels, as suggested by available guidelines. $5,39,40$ We usually increase the dose to reach tacrolimus levels of 4-5 ng/L, and these levels are evaluated biweekly in the first trimester and monthly afterwards. In some patients, especially in those in which the calcineurin inhibitor dose is significantly increased (even with therapeutic levels), hyperkalemia or graft dysfunction can occur without any other cause, and usually resolve after reducing the dosage.

Although rejection episodes are rare during pregnancy (around 3 to $4 \%$ ), when they occur, therapy will include iv steroids, plasmapheresis, Ivlg or rituximab. There is currently insufficient data to recommend the use of rituximab during pregnancy as it may causes neonatal B-cell depletion and although there are several case reports, its longterm effect is still unknown.
Pregnancy is a risk factor for hyperimmunization. Studies reveal that around $30 \%$ of patients can develop anti-HLA antibodies during pregnancy. Additionally, 50 to $75 \%$ of patients will have anti-HLA antibodies if more sensitive detection methods are used (single bed antigens). However, anti-HLA levels seem to decrease and/or disappear 1 to 2 years after gestation, possibly because fetal-antigens-primed maternal T cells are hypofunctional and highly sensitive to immunosuppression. ${ }^{10}$ Nevertheless, anecdotal case reports of acute rejection following pregnancy have been reported, with donor specific antibody emergence, especially when fetus/paternal HLA typing is similar to that of the donor. ${ }^{41}$

Currently, there is no evidence to support increasing immunosuppression postpartum, but close surveillance in patients with donor/ father shared HLA typing could be helpful in identifying patients at risk of rejection.

\section{POSTNATAL MANAGEMENT OF WOMEN WITH RENAL DISEASE}

Non-steroidal anti-inflammatories (NSAIDs) are frequently prescribed as postpartum analgesics, but in women with CKD those agents should be avoided, especially in patients with eGFR $<30 \mathrm{ml} / \mathrm{min}$ due to the possibility of renal dysfunction or fluid retention. ${ }^{21}$

After delivery, renal function and proteinuria should be evaluated, particularly in patients with acute kidney injury and/or de novo proteinuria/increased baseline proteinuria. In PE, proteinuria usually declines fairly rapidly, sometimes remitting entirely in the first month, although in some cases this can take months to happen. As such, if PE was suspected and renal function is improving, renal biopsy will be delayed for at least 3 months. Importantly, PE can occur with active 
urine sediment and histologic changes can persist for as long as 18 months. ${ }^{42}$ For these reasons, an early biopsy could be misleading.

All patients with CKD or a new diagnosis of renal disease are evaluated postpartum at the Nephro-Obstetric clinic. Patients with previously known CKD are then referred to their renal physician in order to maintain follow up.

After birth, antihypertensive therapy needs to be adjusted, especially in patients with $\mathrm{PE}$ or hypertension aggravation during pregnancy. Patients under immunosuppression with a calcineurin inhibitor should have their levels evaluated for new dose adjustment in order to avoid nephrotoxicity.

Counselling regarding breastfeeding is of paramount importance, as most CKD patients will have doubts about the safety of therapy. The LactMed database from the National Institutes of Health (NIH) provides an excellent tool regarding the safety of drugs while breastfeeding, as it is updated monthly. Methyldopa, nifedipine and metoprolol are safe during lactation. ACE inhibitors can and should be used in women with hypertension and proteinuria, and of those, enalapril or captopril represent the best option, barely being detectable in breast milk. There is insufficient data on the use of ARB during breastfeeding, and diuretics are generally avoided because of the potential to reduce milk production. ${ }^{15,21,43-45}$ Immunosuppressive agents such as low dose corticosteroids, tacrolimus, CSA, azathioprine and hydroxychloroquine are safe during lactation. Small studies quantifying the quantity of azathioprine, tacrolimus, and CsA in breastmilk suggest that the dose received by the new-born is only a small percentage (usually $<1 \%$ ) of the maternal dose and unlikely to cause injury. $46-49$ On the contrary, mycophenolate mofetil, mTORi, rituximab, cyclophosphamide and eculizumab should be avoided due to limited data.

\section{CONCLUSIONS}

Pregnancy in women with CKD and women with a renal transplant should be planned in advance. Therefore, nephrologists and obstetricians should pursue active counselling to reduce the risks and optimize maternal and fetal outcomes. Management of these women is complex and should involve a multidisciplinary team, closely monitoring maternal and fetal wellbeing during pregnancy.

\section{Disclosure of potential conflicts of interest: none declared}

\section{References}

1. Webster P, Lightstone L, McKay DB, Josephson MA. Pregnancy in chronic kidney disease and kidney transplantation. Kidney Int 2017;91(5):1047-1056.

2. Hladunewich MA, Melamad N, Bramham K. Pregnancy across the spectrum of chronic kidney disease. Kidney Int 2016;89(5):995-1007.

3. Jones DC, Hayslett JP. Outcome of pregnancy in women with moderate or severe renal insufficiency. N EngI J Med 1996;335(4):226-232.

4. Zhang JJ, Ma XX, Hao L, Liu LJ, Lv JC, Zhang H. A systematic review and meta-snalysis of outcomes of pregnancy in CKD and CKD putcomes in pregnancy. Clin J Am Soc Nephrol 2015;10(11):1964-1978.

5. Baker RJ, Mark PB, Patel RK, Stevens KK, Palmer N. Renal association clinical practice guideline in post-operative care in the kidney transplant recipient. BMC Nephrol 2017;18(1):174.

6. Deshpande NA, James NT, Kucirka LM, et al. Pregnancy outcomes in kidney transplant recipients: A systematic review and meta-snalysis. Am J Transplant 2011;11(11):2388-2404.
7. Piccoli GB, Minelli F, Versino E, et al. Pregnancy in dialysis patients in the new millennium: A systematic review and meta-regression analysis correlating dialysis schedules and pregnancy outcomes. Nephrol Dial Transplant 2016;31(11):1915-1934.

8. Barua $M$, Hladunewich $M$, Keunen J, et al. Successful pregnancies on nocturnal home hemodialysis. Clin J Am Soc Nephrol. 2008;3(2):392-396.

9. Hladunewich MA, Hou S, Odutayo A et al. Intensive hemodialysis associates with improved pregnancy outcomes: A Canadian and United States cohort comparison. J Am Soc Nephrol. 2014;25(5):1103-1109.

10. Porrett PM. Biologic mechanisms and clinical consequences of pregnancy alloimmunization. Am J Transplant. 2018;18(5):1059-1067.

11. Magee LA, Dadelszen P, Singer J, The CHIPS randomized controlled trial (control of hypertension in pregnancy study). Hypertension 2016;68(5):1153-1159.

12. Bateman BT, Bansil P, Hernandez-Diaz S, et al. Prevalence, trends, and outcomes of chronic hypertension: A nationwide sample of delivery admissions. Am J Obstet Gynecol 2012;206(2):134e1-134e8.

13. Hypertension in pregnancy. Report of the American College of Obstetricians and Gynecologists' Task Force on Hypertension in Pregnancy. Obstet Gynecol 2013;122(5):11221131.

14. Hypertension in pregnancy: diagnosis and management. NICE guideline. 2019;1-54.

15. ACOG practice bulletin No. 203: Chronic Hypertension in Pregnancy. Obstet Gynecol. 2019;133(1):e26-e50

16. Smith MC, Moran P, Davison JM. EPI-CKD is a poor predictor of GFR in pregnancy. Archives of Disease in Childhood - Fetal and Neonatal Edition 2011:96:Fa99.

17. Koetje PMJL, Spaan JJ, Kooman JP, Spaanderman ME, Peeters LL. Pregnancy reduces the accuracy of the estimated glomerular filtration rate based on Cockroft-Gault and MDRD formulas. Reprod Sci 2011;18(5):456-462.

18. Hladunewich MA, Myers BD, Derby GC, et al. Course of preeclamptic glomerular injury after delivery. Am J Physiol Renal Physiol 2008;294(3):F614-F620.

19. Hogan MC, Reich HN, Nelson PJ, et al. The relatively poor correlation between random and 24-hour urine protein excretion in patients with biopsy-proven glomerular diseases. Kidney Int 2016;90(5):1080-1089

20. National Institute of Clinical and Health Excellence. Diabetes in Pregnancy. Management of diabetes and its complications from pre- conception to the postnatal period, NICE guideline 3. 2015.

21. Wiles K, Chappell L, Clark K, et al. Clinical Practice Guideline Pregnancy and Renal Disease. 2019; $1-87$.

22. Lightstone L, Hladunewich MA. Lupus nephritis and pregnancy: Concerns and management. Semin Nephrol 2017;37(4):347-353.

23. Tektonidou MG, Andreoli L, Limperet M, et al. EULAR recommendations for the management of antiphospholipid syndrome in adults. Ann Rheum Dis 2019;78(10):1296-1304

24. Buyon JP, Kim MY, Guerra MM, et al. Predictors of pregnancy outcomes in patients With lupus. Ann Intern Med 2015;163(3),153-163.

25. Gordon S, Denunzio T, Uy A. Success using tacrolimus in patients with proliferative and membranous lupus nephritis and refractory proteinuria. Hawaii J Med Public Health. 2013;72(4):18-23.

26. Piccoli GB, Daidola G, Attini R, et al. Kidney biopsy in pregnancy: Evidence for counselling? A systematic narrative review. BJOG. 2013;120(4):412-427.

27. Nicolle LE, Gupta K, Bradley SF, et al. Clinical Practice Guideline for the Management of Asymptomatic Bacteriuria: 2019 Update by the Infectious Diseases Society of Americaa. Clin Infect Dis 2019;68(10):e83-e110.

28. Rolfo A, Attini R, Nuzzo AM, et al. Chronic kidney disease may be differentially diagnosed from preeclampsia by serum biomarkers. Kidney Int. 2013;83(1):177-181.

29. Maynard SE, Min JY, Merchan J, et al. Excess placental soluble fms-like tyrosine kinase 1 (sFlt1) may contribute to endothelial dysfunction, hypertension, and proteinuria in preeclampsia. J Clin Invest 2003;111(5):649-658.

30. Thadhani R, Hagmann $H$, Schaarschmidt W, et al. Removal of soluble fms-like tyrosine kinase-1 by dextran sulfate apheresis in preeclampsia. J Am Soc Nephrol. 2016;27(3):903913.

31. Bagon JA, Vernaeve H, De Muylder X, Lafontaine JJ, Martens J, Van Roost G. Pregnancy and dialysis. Am J Kidney Dis. 1998;31(5):756-765.

32. Hou SH. Frequency and outcome of pregnancy in women on dialysis. Am J Kidney Dis 1994;23(1):60-63.

33. Shahir AK, Briggs N, Katsoulis J, Levidiotis V. An observational outcomes study from 1966-2008, examining pregnancy and neonatal outcomes from dialysed women using data from the ANZDATA Registry. Nephrology (Carlton). 2013;18(4):276-284.

34. Lin CT, Liu XN, XU HL, Sui HY. Menstrual disturbances in premenopausal women with end stage renal disease: A cross-sectional study. Med Princ Pract. 2016;25(3):260-265.

35. Van Eps C, Hawley C, Jeffries J, Johnson DW, Campbell S, Isbel N, Mudge DW, Prins J: Changes in serum prolactin, sex hormones and thyroid function with alternate nightly nocturnal home haemodialysis. Nephrology (Carlton) 2012;17:42-47.

36. Shenhav S, Gemer O, Sherman DJ, Peled R, Segal S: Midtrimester triple-test levels in women with chronic hypertension and altered renal function. Prenat Diagn 2003;23:166167

37. Hladunewich M, Schatell D. Intensive dialysis and pregnancy. Hemodial Int. 2016;20(3):339-348.

38. Hebert MF, Zheng $\mathrm{S}$, Hayset $\mathrm{K}$, et al. Interpreting tacrolimus concentrations during pregnancy and postpartum. Transplantation. 2013;95(7):908-915.

39. Kasiske BL, Zeier MG, Chapman JR, et al. KDIGO clinical practice guideline for the care of kidney transplant recipients: A summary. Kidney Int. 2010;77(4):299-311. 
40. Heemann U, Abramowicz D, Spasovski G, Vanholder R. European Renal Best Practice Work Group on Kidney Transplantation. Endorsement of the Kidney Disease Improving Global Outcomes (KDIGO) guidelines on kidney transplantation: a European Renal Best Practice (ERBP) position statement. Nephrol Dial Transplant. 2011;26(7):2099-2106.

41. Sagasaki M, Nakada Y, Yamamoto I, et al. Antibody-mediated rejection due to anti-HLA$\mathrm{DQ}$ antibody after pregnancy and delivery in a female kidney transplant recipient. Nephrology (Carlton). 2018;23 (2):81-84.

42. Kincaid-Smith P. The renal lesion of preeclampsia revisited. Am J Kidney Dis 1991;17(2):144-148

43. Lightstone L. Renal disease and pregnancy. Medicine 2011;39:497-501.

44. Beardmore KS, Morris JM, Gallery ED: Excretion of antihypertensive medication into human breast milk: A systematic review. Hypertens Pregnancy 2002;21:85-95.

45. Podymow T, August $P$, Umans JG. Antihypertensive therapy in pregnancy. Semin Nephrol 2004;24: 616-625.

46. Sau A, Clarke S, Bass J, Kaiser A, Marinaki A, Nelson-Piercy C. Azathioprine and breastfeeding: Is it safe? BJOG 2007;114(4):498-501.
47. Gardiner SJ, Begg EJ. Breastfeeding during tacrolimus therapy. Obstet Gynecol 2016;107(2):453-455

48. Bramham K, Chusney G, Lee J, Lightstone L, Nelson-Piercy C. Breastfeeding and tacrolimus: Serial monitoring in breast-fed and bottle-fed infants. Clin J Am Soc Nephrol 2013;8(4): 563-567.

49. Morton A. Cyclosporine and lactation. Nephrology (Carlton) 2011;16(2): 249.

\section{Correspondence to:}

Estela Nogueira, MD

Division of Nephrology and Renal Transplantation, Department of Medicine, Centro Hospitalar Lisboa Norte, EPE;

Av. Prof. Egas Moniz MB, 1649-028 Lisboa

E-mail: estelanogueira@gmail.com 